\title{
Phrasal Verbs in Malaysian ESL Textbooks
}

\author{
Abdolvahed Zarifi (Corresponding author) \\ Department of Language and Humanities Education, Faculty of Educational Studies \\ Universiti Putra Malaysia, 43400 UPM SERDANG, Selangor, Malaysia \\ Tel: 60-136-698-284 E-mail: vahed_zarifi@yahoo.com \\ Jayakaran Mukundan \\ Department of Language and Humanities Education, Faculty of Educational Studies \\ Universiti Putra Malaysia, 43400 UPM SERDANG, Selangor, Malaysia \\ E-mail: jaya@educ.upm.edu.my
}

Received: January 26, 2012

Accepted: February 14, 2012

Published: May 1, 2012

doi:10.5539/elt.v5n5p9

URL: http://dx.doi.org/10.5539/elt.v5n5p9

\begin{abstract}
It is often claimed that ELT textbook materials are mostly unwittingly intuitively- rather than empirically-based and that this bookish form of language is far from reflecting the real language use. The present study, by adopting a corpus-based approach, tends to shed light on the extent of agreement between the Malaysian ESL textbooks and the empirical corpus findings with regard to the inclusion and presentation of the phrasal verb combinations. Results, it is hoped, can provide enough insight into the textbook-related difficulties nonnative speakers might experience in learning phrasal verbs and the areas of the pedagogy in need of supplementary activities.
\end{abstract}

Keywords: Corpus Linguistics, Phrasal verbs, Textbook analysis, ESL materials

\section{Introduction}

Syntax and phonology were, in the not-so-distant past, overemphasized at the expense of lexicon in language study and instruction as well (Ellis, 1985). They were considered as the rule-governed aspects of the language and susceptible to scientific investigation (Chomsky, 1965). Lexicon was, on the other hand, considered as "an appendix of the grammar, a list of basic irregularities" (Bloomfield, 1933, p. 274), or "a repository of idiosyncrasies" (Atkins et al., 1994, p. 8). To put it into perspective, while grammar was looked at as a regular 'closed' system and therefore analyzable as a set of rules, the lexicon was viewed as an 'open' system allowing for new items to enter at any time, hence irregular and idiosyncratic (Howarth, 1998).

While phrasal verbs are sometimes referred to as the multi-word middle ground between "syntax and lexis", (Gass \& Selinker, 2001) as they comprise one open-class item (the verb) and one closed-class item (the particle) (Howarth, 1998), they are generally recognized as word-level entities included in the lexicon (Cappelle, 2005; Chomsky, 1965; Jackendoff, 1997). As such, they were, like other components of the lexicon, ignored in the related research as an idiosyncratic linguistic phenomenon.

The hegemony of grammar in linguistic studies was, nevertheless, challenged by such key developments in the field as the lexical syllabus (Willis, 1990), with emphasis upon the highly frequent vocabulary and the recognition of the critical role of multi-word expressions in language acquisition and fluency (Thornbury, 2002). These developments were fuelled by the emergence of the new science of corpus linguistics and the development of machine-readable corpora in the 1960s. The consequent attention to the lexicon gave rise to the new sub-discipline of phraseology (Cowie, 1994), which came to the fore in the linguistic studies after Bolinger (1979, p. 96) observed that speakers of any language have at their disposal an immense wealth of ready-made multi-word units to use rather than requiring "to build everything starting with lumber, nails, and blueprint".

Phrasal verbs (e.g., sit down, turn on, come across, run out, etc.) have been defined as combination of a verb proper and a morphologically invariable particle functioning as a single syntactic and lexical unit (Darwin \& Gray, 1999). The syntactic integrity is embodied in the word order and intonation unit of the combination, the violation of which leads to grammatical incoherence. In the same way, the lexical unity is achieved by the fact that the total meaning of the combination cannot be conveyed by any of the components alone. 
Phrasal verbs are claimed to be one of the most notoriously challenging phenomena of English language instruction (Celce-Murcia \& Larsen-Freeman, 1999; Gardner \& Davies, 2007; Siyanova \& Schmitt, 2007). Cowie (1993, p. 38) looks at them as "a nettle that has to be grasped if students are to achieve native-like proficiency in speech and writing." Despite their rather complicated structure and unpredictable meaning of some combination types, phrasal verbs are of high relevance for ESL/EFL learners because a grasp of them "can be a great asset to learners in acquiring a new language" (Celce-Murcia \& Larsen-Freeman, 1999).

Phrasal verbs are not only a source of problem for EFL and ESL speakers of non-Germanic languages but also a source of nuisance for the native speakers of other-than-English Germanic languages. The problems that ESL/EFL learners experience in learning and using these constructions are compounded by the extreme uniqueness, high productivity, wide variability and vast ubiquity of these combinations. To begin with, they are almost unique to Germanic languages like English, German, Dutch, etc. (Celce-Murcia \& Larsen-Freeman, 1999), hence quite alien to learners from non-German languages such as Hebrew, Chinese, Malay, and so on. Second, a small number of lexical verb items in tandem with a very limited number of particles account for all the occurrences of different types of phrasal verbs in the language. In addition, new forms of these combinations are constantly coined and their production is known as "an outpouring of lexical creativeness that surpasses anything else in our language" (Bolinger, 1971, p. xi). Third, some of these structures are likely to appear in more than one grammatical form. The last but not the least, not only are they frequent in informal contexts but also abound in most formal and highly academic forms of the language (Cornell, 1985).

\section{Literature Review}

The phrasal verb combinations have been recently studied in different general corpora. For instance, Gardner and Davies (2007) studied the phrasal verbs in the British National Corpus. Findings indicate that combination of a small number of 20 lexical verbs with 8 adverbial particles (160 cases) accounts for more than one half of the 518,923 phrasal verb occurrences in the mega-corpus. Further analysis indicates that only 25 phrasal verbs account for nearly one third of all phrasal-verb occurrences in the BNC, and 100 phrasal verbs account for more than one half of all such items. Results also reveal that certain forms such as "out, up, down, and back" tend to occur more as particles than as prepositions. In contrast, certain others like "under, by, and across" rarely function as particles but most often do as prepositions. In view of the verbs, a few forms like "pick, point, and carry" are more likely to occur in phrasal verb combinations than to act as lexical items.

In another corpus study, Trebits (2009) investigated the frequency of use of these ubiquitous combinations in the written documents of the European Union (EU). Having adopted an objective definition of the phrasal verbs that would include all cases of verb- particle combinations, he identified and extracted all the occurrences of the phrasal verb forms in the corpus along with statistic information on the most frequent and productive lexical verbs and particle elements forming phrasal verbs. Data analysis enabled the researcher to provide a list of the most productive lexical verbs and particles forming verb + particle constructions in the CEUE. A total of 130 lexical verb-types and 14 particles were identified in a total of 1031 phrasal verb constructions. From the top 50 lexical verbs in the CEUE, eleven items (e.g., base, bring, call, go, make, open, put, report, set, take, work) appear to function in phrasal verb constructions very frequently; moreover, some of them combine with the largest number of adverbial particles.

Finally, exploring the Malaysian ESL learners' use of phrasal verbs in narrative writing, Akbari (2009) found that learners' production of these forms involved some deviations from the prescribed rules for the combinations and they mostly resorted to simplification and compensative strategies to overcome their knowledge inadequacies.

\section{Problem Statement}

One major problem confronting materials developers is the overwhelming number of phrasal verbs in the available sources to choose from. Pedagogically speaking, given the sheer number of phrasal verbs in a native speaker's repertoire and the limited volume of course books, it is impossible to include every phrasal verb for instruction and nor will all of these structures be of equal use and efficiency for learners. Although they may not be every textbook writer's pet language phenomenon to deal with, so to speak, it comes as no surprise that phrasal verb combinations have found their way in any ELT materials. This being the case, of pedagogical concern to the researcher in the current study was whether the selection and presentation of these combinations in the Malaysian ESL textbook materials is empirically justified. This is deemed imperative as Mukundan (2004) holds that Malaysian prescribed ESL textbooks were prepared through a process that involved assumption and as such the writers intuited what they considered to be the only relevant and acceptable language input for the target ESL learners. More specifically, it is often observed that course books present phrasal verbs in a way that implies that there are no systematic patterns with these combinations or fail to create learnable patterns or even create patterns of the wrong kind (Side, 1990). 
Further argument for the present investigation comes from Cornell (1985), cited in Sjoholm (1995), reporting that learning of phrasal verbs in classroom contexts is inescapably unsuccessful perhaps because the bookish form of language practiced at school fails to reflect the real language use.

In line with the previous argumentation, this study was carried out on the spoken parts of the Malaysian ESL textbooks Form 1, Form 2, Form 3, Form 4 and Form 5 to:

1. Determine the most frequent particles in the corpus and how often they function as particles versus prepositions.

2. Determine the most frequent lexical verbs used in phrasal verb constructions and the extent to which they interact with various particles.

3. Examine the extent of appropriateness of the selection and presentation of the phrasal verb forms in this pedagogic corpus

\section{Methodology}

The present study is a corpus-based content analysis of the textbook materials prescribed for use by the Malaysian ESL learners at the secondary level. It tries to, through a descriptive quantitative approach, look for the possible patterns with the phrasal verbs and their constituents in the target corpus. The quantitative content analysis serves the goal sensibly well as Conrad (2005) contends that identification of patterns of language use necessarily involves making a quantitative assessment as it is presupposed that typical patterns must be more frequent than unusual or unique uses of language.

\subsection{Population and Sampling}

The spoken parts of the ESL textbooks prescribed for secondary level students of Form 1 through Form 5 comprise the population of this corpus study. The corpus, consisting of about 20,000 running words, was studied to identify the frequency occurrences of the phrasal verb combinations and their presentation against the BNC as the reference corpus. The BNC (accessible from, http://www.natc orp.ox.ac.uk/) is a 100-million-word corpus of written and spoken language from a wide range of genres. It should be pointed out that this study adopts a comprehensive data sampling (Ary, Jacob, Razavieh, \& Sorensen, 2006) as every phrasal verb occurring in the corpus is included in the analysis.

\subsection{Instrumentation}

In the present study, use was made of the WordSmith tools version 4.0 to search the corpus of the study for the potential phrasal verbs. This software comprises a suite of six tools from which only Wordlist and Concord functions were of relevance to the study. The WordList tool was used to determine the frequency occurrence of the potential preposition/particle forms that help form phrasal verbs in the corpus. The WordList product served as a basis upon which, in the next stage, the Concord tool was run to create the concordance list of the phrasal verb combinations through identifying every occurrence of a particle (Part) headed by a lexical verb (V).

\subsection{Data Gathering}

Of major methodological issue in this corpus-based study was the extraction of phrasal verb items from among the potential structures. As English phrasal verbs are highly productive in terms of the variety of the lexical verbs that can combine with the potential particles, it is almost impossible to list all the verb components of these structures. The number of particles is, however, quite limited. For instance, the Collins Cobuild Dictionary of Phrasal Verbs (1995) includes a comprehensive list of 48 possible English particles. Likewise, Vorgelegt Von (2007) lists 25 adverbial particles, identified by Johansson and Hofland (1989) and Quirk et al. (1985). However, since some elements like 'overboard' is said to appear in 'idioms' rather than in phrasal verbs (Oxford Advanced Learner's Dictionary, $7^{\text {th }} \mathrm{ed}$.), and some others like 'past' failed to have appearance in the corpus, the researcher reduced the list to a minimum of 19 particles which runs as in table 1.

With this list in mind, first the WordList function of the WordSmith software version 0.4 was run to locate the occurrence of all the potential particles in the corpus. Then, use was made of the Concordance tool to peruse the particles and extract all the phrasal verbs.

The second step in data collection consisted of software queries to identify and report every occurrence of a particle/preposition headed by a lexical verb. Instead of searching the entire concordances of the particle/preposition forms, the search was limited by locating these elements and then looking for the rightmost verbs occurring to the left. As phrasal verb combinations behave syntactically differently, in that the particle element is likely to fall at any distance from its associated lexical verb, the software was programmed to search for these structures within different lengths. In other words, in a phrasal verb structure, the particle could immediately follow the verb $(\mathrm{V}+$ Part), fall within two words $(\mathrm{L}+\mathrm{X}+$ Part), within three words $(\mathrm{V}+\mathrm{X}+\mathrm{X}+$ Part $)$, or within 
four words $(\mathrm{V}+\mathrm{X}+\mathrm{X}+\mathrm{X}+$ Part). For example, "come across" is a ' $\mathrm{V}+$ Part' phrasal verb because there occur no other elements between the V (come) and the Part (across), but "turn the TV on" is a 'V+X+X + Part' phrasal verb structure as there are two intervening words (the article "the" and the noun "TV") between the V (turn) and the Part (on). The query was, however, limited to this length as the search beyond this length scenario led to no results. It is interesting to point out that while it is possible for a particle element to function as a preposition as well, at this stage no distinction was made between these grammatical functions since the structure needed to undergo a set of specific tests to qualify as a phrasal verb combination.

The third step involved the identification of phrasal verb forms from their orthographically associated structures of prepositional verbs. To this end, the following set of criteria developed by Darwin and Gary (1999) was employed:

(1) Whether the repetition of the particle component without its verb proper is permissible (particles cannot be repeated but prepositions can).

(2) Whether the combination allows for the insertion of adverbs ending in -ly (phrasal verbs do not allow such insertion but prepositional verb forms do).

(3) Whether forefronting of the particle is permissible (phrasal verbs do not allow forefronting of particle but prepositions can be forefronted).

(4) Whether the particle is stressed or not (in phrasal verbs particles are stressed but not in prepositional verb combinations).

(5) Whether the verb and its particle form an intonation unit (phrasal verbs form an intonation unit but prepositional verb forms do not).

(6) Whether the particle can answer the question "where" (the particle cannot answer "where" questions but prepositions can).

In the fourth step the researchers, keeping the research questions in mind, followed a problem-based annotation method and tagged all the occurrences of potential adverbial particles in the corpus. For instance, such tags as 'Part', 'Prep', 'VP' and 'Other' were assigned to the particles, prepositions, phrasal verbs and other functions of the particle/preposition (noun, verb, etc.), respectively.

In the next stage, the outcomes were lemmatized to have all the inflectional forms of each lexical verb counted together. In other words, lexical verbs were dealt with as they appear in the form of dictionary entries (McEnery, Xiao, \& Tono, 2006). For instance, the forms "turn, turns, turning, and turned" were grouped together under the lemma "TURN". For the purpose of making an orthographic distinction between lemmas and individual lexical forms, lemmas are presented in uppercase letters (Stubbs, 2001).

In order to analyze the identified combinations in terms of their frequency of occurrence, the collected data were finally presented in a spreadsheet form. This form enabled us to calculate the frequency rate of each particle, frequency of each phrasal verb, frequency of each verb with different particles, frequency of each particle with different verbs, frequency rankings, and so forth.

\section{Results and Discussion}

Table 2 presents the total number of all grammatical tags for each of the 19 preposition-particle forms in the spoken part of the Malaysian pedagogic corpus. It also shows the number of times each of these forms was tagged as a particle as opposed to a preposition or other grammatical categories. There exist a total of 821 of such forms in the corpus out of which only 108 occurrences $(.13 \%)$ turn out to act as particles forming phrasal verb structures. Tests of particle/preposition identification revealed that most of the cases (687) serve as prepositions and a small number of them (26) act as other functions such as adverbs, adjectives and nouns in the corpus. The sheer number of prepositions is due to the fact that some forms like "with and by" tend to serve almost exclusively as prepositions in the English language. Furthermore, those others that could function as particles are infrequently preceded by any lexical verb in the corpus. In other words, they fail to act as particles depending upon the context in which they appear. Moreover, not any sequence of verb + preposition/particle form signals a phrasal verb. Therefore, the preposition/particle forms act either as prepositions or other forms most of the time. For instance, 'up' which is mostly used as a particle, does not form a phrasal verb in the utterance "Are you taking mother to Dr Chan for a check-up this morning?" Likewise, there occur a large number of sequences like "I carried the small children out of the bus" that feature prepositional verbs rather than phrasal verbs.

These particle/preposition forms behave quite idiosyncratically with regard to the functions they carry in the corpus. While some forms like 'with and by' act exclusively as prepositions, some others like 'back' serve exclusively as particles. There are still a few other forms such as 'up and out' which act more as particles than as prepositions and 
there exist some other items like 'for and on' which act mostly as prepositions. The overall totals indicate that these forms function less than $.13 \%$ of the time as adverbial particles. This can be raised as a remarkable disadvantage of the spoken section of the textbooks as empirical corpus-based evidence indicates that these forms have appeared $15.5 \%$ of the time in phrasal verb constructions in real use of the language (Gardner \& Davies, 2007), that is, 115 times as much as their frequency rate in our pedagogic corpus.

Table 3 reveals the most frequent and prolific particle forms in phrasal verb combinations. Despite the fact that some preposition/particle forms tend to function almost always as prepositions, some forms turn out to be highly frequent in phrasal verb combinations. For instance 'up, out, and down' are among the most frequent items that contribute to form such combinations. Phrasal verb tokens involving these particles account for $67 \%$ of all the combinations in the corpus. Looking at it from another angle, we realize that combination of these three particles with a number of lexical verbs accounts for $77 \%$ of all the phrasal verb lemmas in the corpus. To put this observation into a more practical perspective, acquisition of these three particles and their lexical verb forms would enable the students to understand and use a larger number of phrasal verb constructions of the textbooks language than if they acquired the remaining 16 particles and their associated verb components which cover only $23 \%$ of all the occurrences in the corpus. This can be viewed as a deviation of the textbooks from natural use of the language since combination of 8 particles with 20 lexical verbs has been reported to account for about half of all the combinations in natural language (Gardner \& Davies, 2007).

Table 4 presents the list of the lexical verbs and the potential particles with which they combine to form phrasal verb constructions in the corpus. About 51 lexical verb-types were identified in 66 verb + particle types (e.g., come up, come over, come back, etc.) and in a total of 108 phrasal verb constructions. Not only are some of the verbs of frequent use in phrasal verb structures, but they also combine with a number of different adverbial particles. For example, 'come' as the most prolific verb form combine with eight different particles such as 'about, back, down, in, on, over and up' to form phrasal verbs. 'Go' with five different particles and 'get and look' with three different particles each were other prolific verbs in the corpus. The phrasal verbs made up of these four lexical verbs (come, go, look and get) and their accompanying particle forms account for about $27 \%$ of all the verb + particle types in the corpus. In other words, more than 1 out of 4 phrasal verb combinations in the corpus incorporate one of these four forms as their lexical verb component, suggesting the overuse of these verbs at the expense of other verbs of common use in general English.

Table 5 reveals the top 25 phrasal verb lemmas that had a frequency record of two times or more. Altogether, they include $38 \%$ of all the phrasal verb lemmas in the corpus. However, the inclusion and presentation of these units in terms of recycling seem to be far from satisfactory, with some being over-repeated at the expense of some others. As it is shown the unit 'clean up' alone accounts for 10 percent of all the instances of these high frequent forms. Only 8 of these top 25 items are among the top 100 phrasal verb forms in general English. It is interesting to point out that the occurrence frequencies of these shared items are not consistent at all. For instance, while 'turn off' ranks 87 in the BNC reference corpus, it ranks 18 in our corpus.

Of pedagogical concern to ESL English course designers and materials developers are the forms which emerge as frequent in the ESL but not at all so in general English and vice versa. For example, 'clean up and melt down' which are the most frequent forms in this pedagogic corpus are not included in the 100 top phrasal verbs in the general language. Nor are even the lexical verbs acting in these forms among the high frequent lexical verbs in general English. The high frequency of these combinations can be interpreted in light of the writers' tendency to organize the selection of lexical items including phrasal verbs thematically. They probably began with a topic and then went on to introspectively include lexical items that appeared to fit in. What is more, these forms, it can be claimed, are unwittingly overused at the expense of some other forms such as 'work out, turn over, go over, give out, speak out, write out, put away, etc.' which could be pedagogically more valuable.

Table 6 presents the most productive lexical verbs in forming phrasal verb sequences in the corpus. 'Come' turns out to rank fist, combining with seven different particles like 'about, back, down, in, on, over, and up'. Next ranks 'go' combining with 5 and then come 'get and look' each with 3 particles. The lexical verb item of these combinations appears to be idiosyncratically used. While these frequent verbs are also of a high rate of frequency in general language, the number of particles with which they are used is highly restricted compared against the variety of their potential particle components in general English. For instance, while 'get' is used with only 3 different particles (out, over and up) in the corpus, it occurs with more than 12 particles in the real language use.

Although all the phrasal verbs with the lexical verbs 'go and come' in the textbooks corpus are among the most frequent forms in the BNC, there are some forms like 'go off, go along, come off, come through, etc.' that are among the top 100 combinations in general English but absent from our pedagogic corpus. The phrasal verbs with 
'get and look' are a different story. Whereas phrasal verbs such as 'get back, get on, get down, get off and get through' which are among the top 100 phrasal verbs in the BNC are absent from the corpus, it incorporates the phrasal verb 'get over' which is not among the highly frequent combinations. Likewise, though such highly frequent combinations as 'look down and look out' are absent from the corpus, it includes some others like 'look ahead and look after' which are not of high frequency in general English.

Table 7 lists the lemmas of phrasal verbs and their frequency of occurrence. As it is shown, only $37 \%$ of all the phrasal verb lemmas in the corpus have been repeated at all. In other words, most of them $(63 \%)$ are treated as hapax, occurring once in the spoken corpus. Thornbury (2002) reiterates that words with a minimum occurrence of seven times over spaced intervals stand a good chance of being remembered. Likewise, Celce-Murcia and Larsen-Freeman (1983) consider it pedagogically sensible for different aspects of language to be recycled over a period of time. Despite the doubtfulness of pedagogical utility of corpora generated by frequency lists (Howarth, 1998; Widdowson, 1990), Romer (2005) looks at frequencies as a major key in the selection of central lexical items or syntactic structures for instructional purposes, without which the inclusion and prioritization of EFL/ESL teaching materials is both difficult and questionable. Likewise, Kennedy (2002) argues in favor of concentrating initial teaching on language items of high frequency. Indeed, for the ESL learners to master this notoriously challenging aspect of the language, they need to be exposed to the most frequent forms which are by the same token the most useful ones and at the same time revisit them in follow-up activities.

To make a long story short, both the selection and presentation of the phrasal verb combinations in the spoken part of the Malaysian ESL textbooks turned out to be inconsistent with use of these forms in the natural use of the language. If the comparison of the use of these forms in the corpus against the $\mathrm{BNC}$ as the reference corpus cannot be interpreted as possible shortcomings that these ESL textbooks might be suffering from, it at least makes the suggestion that more purposeful phrasal verb items of immediate use need to be included. It also shows that the used forms need to be more effectively recycled and presented in order for the learners to master them with much less effort and more efficiency.

It is necessary to reiterate once more that the statistics in the study is only for the spoken section of the Malaysian ESL textbooks and may vary somewhat across the other sections. However, as the phrasal verbs feature informal and spoken language, one would expect a greater level of consistency between the pedagogy and general language use.

\section{Conclusion}

ESL/EFL learners need to become sensitive to patterns of language elements that are more likely to co-occur than other strings so that they could gain a full command of the language system. Phrasal verbs like other multi-word expressions are known to be incorporated in formulaic language patterns. For ESL/EFL learners to recognize these combinations as formulaic sequences, they need to be exposed to them as a grammatical category frequently enough. It is assumed that formulaic strings, including phrasal verbs, can be recognized due to their higher rate of frequency of occurrence in comparison with other word strings. When each combination is recycled over spaced intervals, learners could recognize the two identifiable orthographic components of each combination as a single big verb. Otherwise they would approach them as ad hoc sequences of lexical verbs and particles, going on to decipher them as lexically and semantically unrelated elements. On the other hand, when the number of phrasal verbs in the textbook is large enough, learners are encouraged to derive the relevant syntactic rules on their own to rationalize, economize and speed up their processing of these fuzzy and challenging combinations.

To sum up, if the ELT materials are to prepare the learners to gain a level of language fluency close to if not the same as that of native speakers, they need to keep pace with research findings. They need to select language materials, both vocabulary and grammatical structures, that are of high relevance and usefulness to the learners. To this end, language items of high frequency should be selected and recycled as it is often stated that it is a waste of time and effort to teach "vocabulary without incorporating the necessary recycling" and non-recurrent language items suggest that they are not worth learning. As a result, not only the pedagogical factor of learning possibility but also profitability issues like encounter probability should to be taken into account in the selection of ELT materials including phrasal verb combinations.

\section{References}

Akbari, O. (2009). A corpus-based study on Malaysian ESL learners' use of phrasal verbs in narrative compositions. Universiti Putra Malaysia, Serdang.

Ary, D., Jacob, L. C., Razavieh, A., \& Sorensen, C. (2006). Introduction to research in education (7th ed.). Wadsworth: Thomson Learning, USA. 
Bolinger, D. (1971). The phrasal verb in English. Cambridge, MA: Harvard University Press.

Cappelle, B. (2005). Particle patterns in English: A comprehensive coverage. Katholieke Universiteit Leuven.

Celce-Murcia, M., \& Larsen-Freeman, D. (1999). The grammar book: An ESL/EFL teacher's course. Boston: H \& H Publishers.

Chomsky, N. (1965). Aspects of the Theory of Syntax. The MIT press.

Conrad, S. (2005). Corpus linguistics and L2 teaching. In E. Hinkel (Ed.), Handbook of Research in Second Language Teaching and Learning, 1. Mahwah, NJ: Lawrence Erlbaum Associates.

Cornell, A. (1985). Realistic goals in teaching and learning phrasal verbs. IRAL-International Review of Applied Linguistics in Language Teaching, 23(1-4), 269-280. http://dx.doi.org/10.1515/iral.1985.23.1-4.269

Darwin, C. M., \& Gray, L. S. (1999). Going after the Phrasal Verb: An Alternative Approach to Classification. TESOL Quarterly, 33(1), 65-83. http://dx.doi.org/10.2307/3588191

Ellis, R. (1985). Understanding second language acquisition. Oxford: Oxford university Press.

Gardner, D., \& Davies, M. (2007). Pointing Out Frequent Phrasal Verbs: A Corpus-Based Analysis. TESOL Quarterly, 41, 339-359.

Gass, S. M., \& Selinker, L. (2001). Second language acquisition: An introductory course (2nd ed.). Hillsdale, NJ: Lawrence Erlbaum.

Howarth, P. (1998). Phraseology and second language proficiency. Applied Linguistics, 19(1), 24-44.

Jackendoff, R. S. (Ed.). (1997). The architecture of the language faculty. Cabridge: The MIT Press.

Kennedy, G. (2002). Variation in the distribution of modal verbs in the British National Corpus. In R. Reppen, S. Fitzmaurica, \& D. Biber (Eds.), Using Corpora to Explore Linguistic Variation (pp. 73-90). Amsterdam: John Benjamins.

McEnery, T., Xiao, R., \& Tono, Y. (Eds.). (2006). Corpus-based language studies: an advanced resource book. New York: Routledge.

Mukundan, J. (2004). A composite framework for ESL textbook evaluation. Universiti Putra Malaysia, Serdang.

Quirk, R., Greenbaum, S., Leech, G., Svartvik, J., \& Crystal, D. (1985). A comprehensive grammar of the English language. New York: Longman.

Romer, U. (2005). Progressives, Patterns, Pedagogy. A Corpus-driven Approach to English Progressive Forms, Functions, Contexts and Didactics. Amsterdam: John Benjamins.

Side, R. (1990). Phrasal verbs: sorting them out. ELT Journal, 44(2), 144-152. http://dx.doi.org/10.1093/elt/44.2.144

Siyanova, A., \& Schmitt, N. (2007). Native and nonnative use of multi-word vs. one-word verbs. IRAL-International Review of Applied Linguistics in Language Teaching, 45, 119-139. http://dx.doi.org/10.1515/IRAL.2007.005

Sjoholm, K. (1995). The influence of crosslinguistic, semantic, and input factors on the acquisition of English phrasal verbs: A comparison between Finnish and Swedish learners at an intermediate and advanced level. Abo: Abo Akademi University Press.

Stubbs, M. (2001). Words and Phrases: Corpus Studies of Lexical Semantics. Oxford: Blackwell.

Trebits, A. (2009). The most frequent phrasal verbs in English language EU documents - A corpus-based analysis and its implications. System, 37(3), 470-481. http://dx.doi.org/10.1016/j.system.2009.02.012

Widdowson, H. G. (1990). Aspects of language teaching. Oxford: Oxford University Press.

Willis, D. (1990). The lexical approach. Language Teaching Publication.

Table 1. English Particles

\begin{tabular}{|l|l|l|l|l|l|l|}
\hline About & After & Ahead & Along & Around & Away & Back \\
\hline By & Down & For & In & Off & On & Out \\
\hline Over & Round & Through & Up & With & & \\
\hline
\end{tabular}


Table 2. Frequency of Particle/Preposition forms and their function in the corpus

\begin{tabular}{|l|l|l|l|l|}
\hline Particle/preposition form & Frequency & Particle & Preposition & Others \\
\hline About & 86 & 1 & 85 & 0 \\
\hline After & 16 & 3 & 13 & 0 \\
\hline Ahead & 2 & 1 & 1 & 0 \\
\hline Along & 3 & 1 & 2 & 0 \\
\hline Around & 7 & 0 & 7 & 0 \\
\hline Away & 22 & 7 & 6 & 9 \\
\hline Back & 3 & 3 & 0 & 0 \\
\hline By & 40 & 0 & 39 & 1 \\
\hline Down & 18 & 15 & 2 & 1 \\
\hline For & 156 & 4 & 152 & 0 \\
\hline In & 193 & 7 & 184 & 2 \\
\hline Off & 7 & 6 & 1 & 0 \\
\hline On & 96 & 4 & 85 & 7 \\
\hline Out & 32 & 23 & 9 & 0 \\
\hline Over & 11 & 3 & 8 & 0 \\
\hline Round & 1 & 0 & 1 & 0 \\
\hline Through & 9 & 2 & 7 & 0 \\
\hline Up & 33 & 28 & 0 & 5 \\
\hline With & 78 & 0 & 77 & 1 \\
\hline Total 19 & $\mathbf{8 1 3}$ & $\mathbf{1 0 8}$ & $\mathbf{6 7 9}$ & $\mathbf{2 6}$ \\
\hline
\end{tabular}

Table 3. Most productive particle forms

\begin{tabular}{|l|l|l|}
\hline Particle form & Frequency & No. of lemmas \\
\hline Up & 28 & 17 \\
\hline Out & 23 & 13 \\
\hline Down & 15 & 7 \\
\hline
\end{tabular}


Table 4. Lexical verbs and particles forming PVs in the corpus

\begin{tabular}{|c|c|c|c|c|c|c|c|c|c|c|c|c|c|c|c|}
\hline LV & About & After & Ahead & Along & Away & Back & Down & For & In & Off & On & Out & Over & Through & Up \\
\hline Break & & & & & & & 1 & & & & & & & & 1 \\
\hline Come & 1 & & & & & 1 & 1 & & 1 & & 2 & & 1 & & \\
\hline Look & 1 & 3 & & & & & & & & & & & & & 1 \\
\hline Invite & & & & 1 & & & & & & & & & & & \\
\hline Call & & & & & & 1 & & & & & & & & & 2 \\
\hline Throw & & & & & 3 & & & & & & & & & & \\
\hline Take & & & & & 1 & & & & & & & & & & \\
\hline Wash & & & & & 1 & & & & & & & & & & \\
\hline Go & & & & & & 1 & & & & & 2 & 2 & 1 & 2 & \\
\hline Cut & & & & & & & 4 & & & & & & & & \\
\hline Fall & & & & & & & 2 & & & & & & & & \\
\hline Melt & & & & & & & 5 & & & & & & & & \\
\hline Move & & & & & & & 1 & & & & & & & & \\
\hline Sit & & & & & & & 1 & & & & & & & & \\
\hline Care & & & & & & & & 2 & & & & & & & \\
\hline Cater & & & & & & & & 1 & & & & & & & \\
\hline Stand & & & & & & & & 1 & & & & & & & \\
\hline Fill & & & & & & & & & 2 & & & & & & \\
\hline Hand & & & & & & & & & 1 & & & & & & \\
\hline Join & & & & & & & & & 1 & & & & & & \\
\hline Reel & & & & & & & & & 1 & & & & & & \\
\hline Start & & & & & & & & & & 1 & & & & & \\
\hline Switch & & & & & & & & & & 3 & & & & & \\
\hline Turn & & & & & & & & & & 2 & & & & & \\
\hline Carry & & & & & & & & & & & & 3 & & & \\
\hline Check & & & & & & & & & & & & 1 & & & \\
\hline Eat & & & & & & & & & & & & 3 & & & \\
\hline Find & & & & & & & & & & & & 4 & & & \\
\hline Get & & & & & & & & & & & & 1 & 1 & & 1 \\
\hline Help & & & & & & & & & & & & 1 & & & \\
\hline Try & & & & & & & & & & & & 2 & & & \\
\hline Point & & & & & & & & & & & & 1 & & & \\
\hline Reach & & & & & & & & & & & & 2 & & & \\
\hline Run & & & & & & & & & & & & 1 & 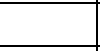 & & \\
\hline Fling & & & & & & & & & & & & 1 & & & \\
\hline Write & & & & & & & & & & & & 1 & & & \\
\hline Wake & & & & & & & & & & & & & & & 2 \\
\hline Use & & & & & & & & & & & & & & & 1 \\
\hline Sign & & & & & & & & & & & & & & & 1 \\
\hline Ring & & & & & & & & & & & & & & & 1 \\
\hline Pick & & & & & & & & & & & & & & & 1 \\
\hline Light & & & & & & & & & & & & & & & 1 \\
\hline Keep & & & & & & & & & & & & & & & 2 \\
\hline Wrap & & & & & & & & & & & & & & & 1 \\
\hline Put & & & & & & & & & & & & & & & 1 \\
\hline Hurry & & & & & & & & & & & & & & & 2 \\
\hline Cheer & & & & & & & & & & & & & & & 1 \\
\hline Give & & & & & 2 & & & & & & & & & & 4 \\
\hline Clean & & & & & & & & & & & & & & & 7 \\
\hline
\end{tabular}


Table 5. Top 25 PV Lemmas (more than one frequency of occurrence)

\begin{tabular}{|l|l|l|l|l|}
\hline PV Lemma & Frequency & Cumulative frequency & Percentage of cumulative frequency & Rank in the corpus \\
\hline Clean up & 7 & 7 & $10.1 \%$ & 1 \\
\hline Melt down & 5 & 12 & 17.4 & 2 \\
\hline Give up & 4 & 16 & 23.2 & 4 \\
\hline Cut down & 4 & 20 & 29 & 4 \\
\hline Find out & 4 & 24 & 34.8 & 4 \\
\hline Look after & 3 & 27 & 39.1 & 8 \\
\hline Eat out & 3 & 30 & 43.5 & 8 \\
\hline Carry out & 3 & 33 & 47.8 & 8 \\
\hline Throw away & 3 & 36 & 52.2 & 8 \\
\hline Switch off & 3 & 39 & 56.5 & 8 \\
\hline Keep up & 2 & 41 & 59.4 & 18 \\
\hline Hurry up & 2 & 43 & 62.3 & 18 \\
\hline Wake up & 2 & 45 & 65.2 & 18 \\
\hline Reach out & 2 & 47 & 68.1 & 18 \\
\hline Try out & 2 & 49 & 71 & 18 \\
\hline Care for & 2 & 51 & 74 & 18 \\
\hline Fill in & 2 & 53 & 76.8 & 18 \\
\hline Come on & 2 & 55 & 79.7 & 18 \\
\hline Go on & 2 & 57 & 82.6 & 18 \\
\hline Go out & 2 & 59 & 85.5 & 18 \\
\hline Go through & 2 & 61 & 88.4 & 18 \\
\hline Call up & 2 & 63 & 91.3 & 18 \\
\hline Fall down & 2 & 65 & 94.2 & 18 \\
\hline Turn off & 2 & 67 & 97.1 & 18 \\
\hline Give away & 2 & 69 & 100 & 18 \\
\hline
\end{tabular}

Table 6. Most productive LVs in forming PVs

\begin{tabular}{|l|l|l|}
\hline LV & No. of particles & particle \\
\hline Come & 7 & About, back, down, in, on, over, up \\
\hline Go & 5 & Back, on, out, over, through \\
\hline Get & 3 & Out, over, up \\
\hline Look & 3 & After; ahead; up \\
\hline
\end{tabular}

Table 7. Lemma frequency of PV combinations

\begin{tabular}{|l|l|}
\hline Lemma & frequency \\
\hline Clean up & $7(1$ item $)$ \\
\hline Melt down & $5(1$ item $)$ \\
\hline Give up; cut down; find out & $4(3$ items $)$ \\
\hline Look after; eat out; carry out; switch off; throw away & $3(5$ items $)$ \\
\hline $\begin{array}{l}\text { Hurry up; keep up; wake up; reach out; try out; care for; fill in; come on; go on; go out; go through; call up; } \\
\text { fall down; turn off; give away }\end{array}$ & $2(15$ items $)$ \\
\hline $\begin{array}{l}\text { Come about; look ahead; invite along; call back; come back; go back; break down; come down; move down; } \\
\text { sit down; cater for; stand for; come in; hand in; join in; reel in; start off; check out; get out; help out; point } \\
\text { out; run out; fling out; write out; come over; get over; go over; use up; sign up; ring up; pick up; look up; } \\
\text { light up; wrap up; put up; cheer up; get up; come up; wash away; take away }\end{array}$ & $1(40$ items $)$ \\
\hline
\end{tabular}

